\title{
ACT 2018 - Lessons to be learned from the past
}

\author{
Florian Falter ${ }^{1 *}$ and Evelien WM Kemna ${ }^{2}$ \\ ${ }^{1}$ Department of Anaesthesia and Intensive Care, Papworth Hospital, Cambridge, UK \\ ${ }^{2}$ Medlon BV, Medisch Laboratorium Oost-Nederland, Enschede, The Netherlands
}

\begin{abstract}
In this review we summarize the current status of knowledge and outline future directions regarding the use of activated clotting time devices (ACT) for heparin monitoring.

It is over 50 years ago that Paul Hattersley first described the ACT and 40 years ago it was first used as a simple method of heparin management during extracorporeal circulation. Today, ACT is the primary test for monitoring heparin activity in cardiac and vascular operating rooms, intensive care and hemodialysis units as well as in the catheter lab. Without appropriate anticoagulation clot will start to form during these procedures, with a high chance of a fatal event occurring. Currently, there are several POC methods available for ACT measurement, however results obtained with different devices can vary substantially. Furthermore, the target ACTs which are described in guidelines are mostly empiric or based on small-scale studies done with one or different POC ACT devices. Moreover, it is important to realize that there is no "gold standard" ACT method and therefore no "true" ACT. The ACT has gone unchallenged for a long time. Being mostly "clinician owned' we have come to accept that, in the absence of a gold standard, there is no way to determine if any one of the commercially available devices measures a true ACT value. The lesson to be learned from the last 40 years is that clinicians', laboratory staff's and manufacturers' approach to the ACT needs to become more collaborative, open and truly multidisciplinary in order to stand up to the level of scrutiny that is increasingly demanded in modern healthcare.
\end{abstract}

\section{Abbreviations: ACT: Activated Clotting Time; CBP: Cardiopulmorary Bypass; POC: Point of Care. \\ ACT 2018 - Are there any lessons to be learned from the past?}

In the absence of adequate anticoagulation, blood stasis or contact with artificial, non-biological surfaces is likely to lead to activation of the clotting cascade with potentially fatal consequences. It is therefore mandatory to ensure that appropriate anticoagulation has been achieved for any form of extracorporeal circulation and any circumstance where foreign material, such as large-bore catheters, is introduced into the arterial side of the circulation for extended periods of time.

Conventional cardiopulmonary bypass (CPB) circuits are made up of several meters of plastic tubing, a plastic reservoir and a membrane oxygenator. Without appropriate anticoagulation clot will start to form in the circuit within minutes of commencing bypass, with a high chance of a fatal event occurring. Despite being less invasive in nature, electrophysiology procedures in the catheter lab carry a $1-5 \%$ risk of thromboembolic complications without anticoagulation [1]. In addition to preventing major untoward events, the level of anticoagulation throughout the procedure must be adequate to stop 'microvascular' clot formation. In their most severe form microvascular clots may lead to a patient's death, but they are more often accused of causing post-operative organ damage such as neurological dysfunction or renal failure.

To this day heparin is the preferred agent for anticoagulation worldwide because of it its cheap price, relative ease of use, predictable onset of action and the ready availability of the antidote protamine.
The ability to quickly and reliably monitor whole blood coagulation is crucial for the safe management of patients undergoing heparin therapy. Presently the activated clotting time (ACT) remains the primary test for monitoring heparin activity in cardiac and vascular operating rooms, intensive care and hemodialysis units as well as in the catheter lab.

\section{The activated clotting time}

It is over 50 years ago that Paul Hattersley first described the ACT [2] and over 40 years ago that Hill published his experience with it as 'a simple method of heparin management during extracorporeal circulation' [3]. The original version used diatomaceous earth as an activator; the processing of the sample was rather questionable by today's standards, requiring it to be placed into a pre-warmed tube sitting in a water bath or on a heating plate while it was being observed and the time until the blood had clotted was measured by hand. The high variability these early results generated might to some extent explain the large differences in ACT values required for safe commencement of $\mathrm{CPB}$ between institutions $[4,5]$.

The first commercial device was launched by Becton Dickinson Company (BD, Franklin Lakes, NJ, USA); the first device automating

${ }^{\star}$ Correspondence to: Florian Falter, Department of Anaesthesia and Intensive Care, Papworth Hospital, Cambridge, CB23 3RE, UK, Tel: +44 1480 364406; E-mail: florian.falter@gmail.com

Key words: activated clotting time, heparin monitoring, point of care, cardiology, anticoagulation, hemostasis

Received: February 20, 2019; Accepted: March 05, 2019; Published: March 10 2019 
end-point detection, temperature control and counting of time elapsed was introduced by Hemochron (ITC, Edison, NJ, USA). Both machines attempted to standardize the testing process using Hattersley's formula and celite, a commercially available inert silicious earth, as activator. These systems terminated the testing process when a sufficient mass of clot had been formed. To this day the majority of devices on the market utilizes this testing principle. The methods used to detect the presence of clot include the cessation of the sample flowing through an hourglass-like narrowing, the displacement of a magnet, the slowing movement of a plunger or the change in the photo-optic properties of blood as it thickens. The common denominator for all devices using this technology is that they do not detect the onset of clotting but their end point is the formation of late stage clot. The variability in the time needed between onset of clotting and the formation of a significant clot is likely to contribute to the poor reproducibility that plagues the ACT.

There are two notable exceptions to this test principle. Firstly the i-STAT ${ }^{\mathrm{rix}}$ (Abbott, Princeton, NJ USA), which relies on amperometric detection of an electroactive compound formed during the common pathway of the clotting cascade to measure the ACT, i.e. its end point is at the beginning of clot formation and not the final product. Secondly, the Hepcon Heparin Management System Plus (HMS Plus ${ }^{\mathrm{mx}}$, Medtronic, Minneapolis, MN, USA) calculates the heparin dose required, based on a heparin dose response. This system is able to measure heparin concentrations during $\mathrm{CPB}$ and calculates a protamine dose at the point of desired reversal.

All current tests are cartridge-based; consumables can be stored outside the fridge for reasonable periods of time and take up little space. The devices are small, portable and easy to use at the point of care (POC), providing the following advantages over coagulation tests that need to be processed in the core lab:

fast draw-to-result time

no risk of sample degradation over time

minimal risk of samples being mislabeled or mishandled

non-lab staff are able to perform the test.
The truly unique features about the ACT are that

it is a blood test almost exclusively run by clinicians without much input from the lab

it does not have a reference range

it does not have a true value

its reference range not only varies from institution to institution but is defined by historic preference rather than science.

An analogy comparing the ACT with a dartboard whose bull's eye changes from pub to pub is tempting!

\section{Different ACT device, different ACT result}

All ACT devices report their result in seconds. However, the way they generate these results varies greatly between manufacturers and even between devices from the same company. An overview over the most widely used POC devices, their activators and detection technique is shown in Table 1. A number of devices offer additional utilities such as pre-warm and non pre-warm or $\mathrm{CPB}$ and non- $\mathrm{CPB}$ measuring modes or low and high range ACT cartridges. Unfortunately, there is no consensus amongst clinicians regarding the use of these features.

Currently there are several POC methods available for ACT measurement, however results obtained with different devices can vary substantially [6]. The American College of Cardiology Foundation/ American Heart Association guidelines for management of STEMI are a just one example of this. During primary percutaneous coronary intervention (PCI) procedures they recommend a target ACT of 250 to 300 s when using the Hemotech device and 300 to 350 s when using the Hemochron [7].

Several studies have attempted to compare the performance of current ACT tests. The majority of the studies involve Hemochron, Medtronic or i-STAT devices.

Schussler et al compared the i-STAT ACT with Hemochron during PCI and concluded that the difference in results was not clinically significant [8]. Paniccia et al. confirmed this during CPB and during

Table 1. An overview of the most widely used POC devices, their activators and detection technique

\begin{tabular}{|c|c|c|c|c|c|}
\hline Manufacturer & Device & Test setup & Reagent & Detection method & Endpoint \\
\hline \multirow[t]{2}{*}{$\begin{array}{c}\text { Medtronic } \\
\text { (Minneapolis, MN, USA) }\end{array}$} & ACT plus & ACT LR & Celite & Mechanical & Clot formation \\
\hline & HMS plus & ACT HR & Celite & Mechanical & Heparin titration and dose response \\
\hline $\begin{array}{c}\text { Sienco } \\
\text { (Boulder, CO, USA) }\end{array}$ & Sonoclot & $\begin{array}{c}\text { kACT } \\
\text { gbACT+ Kit } \\
\text { sonACT Kit }\end{array}$ & $\begin{array}{l}\text { Kaolin } \\
\text { Glass bead } \\
\text { Celite }\end{array}$ & Mechanical & Clot formation \\
\hline \multirow[t]{2}{*}{$\begin{array}{l}\text { International Technidyne } \\
\text { (Edison, NJ, USA) }\end{array}$} & $\begin{array}{l}\text { Hemochron } \\
\text { Jr. Signature, } \\
\text { Signature+ } \\
\text { Signature Elite }\end{array}$ & $\begin{array}{l}\mathrm{ACT} \text { and } \mathrm{ACT} \text { low } \\
\text { range }\end{array}$ & $\begin{array}{c}\text { Mixture of silica, kaolin and } \\
\text { phospholipids }\end{array}$ & Mechanical, optical & Clot formation \\
\hline & Hemochron response & $\begin{array}{c}\text { cACT } \\
\text { kACT } \\
\text { Glass activated ACT }\end{array}$ & $\begin{array}{c}\text { Celite } \\
\text { Kaolin in glass tube, } \\
\text { Glass beads in plastic tubes }\end{array}$ & Mechanical & Clot formation \\
\hline $\begin{array}{c}\text { Instumentation } \\
\text { Laboratory } \\
\text { (Lexington, MA, USA) }\end{array}$ & GEM PCL & $\begin{array}{c}\text { ACT, } \\
\text { ACT-LR }\end{array}$ & $\begin{array}{l}\text { Kaolin and silica } \\
\text { Celite }\end{array}$ & Mechanical, optical & Clot formation \\
\hline \multirow[t]{2}{*}{$\begin{array}{l}\text { Helena Laboratories } \\
\text { (Beaumont, TX, USA) }\end{array}$} & Cascade Abrazo & cACT (LR) & Celite & Mechanical, optical & Clot formation \\
\hline & Actalyke XL/Mini II & $\begin{array}{c}\text { cACT } \\
\text { kACT } \\
\text { glass ACT } \\
\text { MAX ACT }\end{array}$ & $\begin{array}{c}\text { Celite } \\
\text { Kaolin } \\
\text { glass } \\
\text { Mixture of all }\end{array}$ & two-point electromechanical & Clot formation \\
\hline $\begin{array}{l}\text { Abbott Laboratories } \\
\text { (Princeton, NJ, USA) }\end{array}$ & i-STAT & $\begin{array}{l}\mathrm{cACT} \\
\mathrm{kACT}\end{array}$ & $\begin{array}{l}\text { Celite } \\
\text { Kaolin }\end{array}$ & Electrochemical & $\begin{array}{c}\text { Amperometric detection of first thrombin } \\
\text { formation }\end{array}$ \\
\hline
\end{tabular}


hemodialysis. However, this study also reports that results were statistically different when high levels of heparin were administered [9]. A small scale study by Maslow et al verifies the lack of agreement when high doses of heparin are used and reports that the Hemochron yielded higher ACT values than the i-STAT [10]. In contrast, a recent large multi-center study comparing Hemochron Signature and i-STAT found the latter to systematically return higher measurements [11].

Another study comparing the Hemochron Jr. Signature with the Medtronic ACT Plus during CPB showed a good correlation between the two devices with the Hemochron yielding lower readings [12]. In contrast, results from PCI trials showed that Medtronic ACT values were consistently lower when compared to Hemochron [13]. Unsurprisingly a further comparison involving three ACT devices - GEM PCL (Instrumentation Laboratory, Lexington, MA, USA), Hemochron and Medtronic - during cardiovascular surgical procedures confirmed that ACT results generated by these devices could not be used interchangeably [14].

The majority of these studies do not specify activator or cartridge type and measuring mode, some do not even specify the device where a company has more than one on the market. These deficiencies in reporting might go some way in explaining the contrasting results, making the comparison of the results challenging.

\section{The labs' perspective}

Arguably the ACT is the first true POC test, performed by clinical staff at patients' side in the operating room, the catheter lab or any other clinical location where procedural anticoagulation is required. This has largely been done without any involvement of laboratory medicine, allowing clinicians to 'own' the ACT for many years. This practice is in sharp contrast with international guidelines, which state that POC devices fall under the responsibility of the laboratory (ISO22870). In plain text this means that laboratory professionals have an obligation to be involved in all matters ACT, independent of whether testing takes place within the laboratory or at the patient's side. Like any other POC test the ACT should be approached in a multidisciplinary fashion, involving lab staff as well as clinicians, in order to provide optimal patient care by guaranteeing appropriate use and the highest standard of testing and reporting.

The ISO22870 recommends that internal quality control and external quality assessment procedures be applied in a way that ensures immediate and ongoing control of result generation. Yet, internal quality control alone is not sufficient. It may confirm that a test is precise, however, that does not necessarily make it accurate. Some form of external assessment is essential to confirm accuracy and is recommended in the regulatory standard. Unfortunately, at this point in time there is no agreed formal external quality assessment program, which could enable clinicians and lab staff to compare different ACT devices to each other [15].

\section{Analytical performance and result reproducibility}

There are several publications reporting on reproducibility of results in different ACT devices. Ojito et al. [16] notably compared the reproducibility of four different ACT devices, Medtronic HMS, ACTplus, Hemochron Signature Elite and i-STAT, during ex vivo circulation of heparinised donated blood. Whereas Bosch and colleagues investigated the repeatability of the GEM PCL, the Hemochron 801 and Medtronic II during cardiovascular operations requiring unfractionated heparin therapy with $200-300 \mathrm{IU} / \mathrm{kg}$ [14]. Both studies showed the Hemochron devices to have the highest variability while i-STAT and Medtronic showed the best reproducibility of results. A comparison between the Actalyke and the Hemochron 8000 during CBP showed higher reproducibility of the former in the lower ACT range [17]. The largest multi-center study in this area to date compared the reproducibility of results of i-STAT vs. Hemochron Signature Jr. for high dose heparin during cardiac surgery. The authors showed that the i-STAT provides a more reliable and reproducible test for assessing safe anticoagulation during cardiac surgery on pump [11]. The superior analytical performance of the i-STAT was confirmed in another multi-center study including cardiac surgical and catheter lab procedures [18].

\section{Alternatives to ACT}

Currently, to our knowledge, there is no viable and clinically acceptable alternative to the ACT for ensuring adequate procedural anticoagulation with unfractionated heparin using POC technology.

Heparin management systems such as Medtronic's HMS Plus, make use of the heparin dose response curve to calculate the heparin dose required for an individual patient to reach a certain target ACT. The heparin dose response is calculated by mixing blood with $0,1.5$, and $2.5 \mathrm{U} / \mathrm{ml}$ of heparin, measuring a baseline and two further ACTs. These three measurements and the patient's estimated blood volume are used to calculate the heparin bolus dose. Despite the theoretical advantages, heparin management systems have not been introduced into clinical practice widely and have been found to produce a poor estimate of heparin requirements [19]. Amongst the potential sources of error that have been identified are inaccurate estimation of blood volume, lack of reliability of the measured heparin concentration, inherent inaccuracy of the device and differences between ex vivo and in vivo heparin activity. Additionally the lack of adoption of this technology is likely to be due to the fact that conventional ACT devices are cheaper, simpler to use and familiar to the vast majority of clinicians [20].

Viscoelastic whole blood techniques, such as thrombelastography (TEG, Hemonetics, Braintree, MA, USA) or rotational thrombelastometry (ROTEM, Instrumentation Laboratory, Lexington, MA, USA), measure the time between addition of an activator and the onset of clot formation. They could theoretically be used in a similar way to the ACT, however to our knowledge this approach has never been validated or published.

Although prothrombin time and activated partial thromboplastin time have their place in peri-operative testing of cardiac surgical or catheter lab patients, they are not helpful in assessing procedural anticoagulation. They do not reflect the complexity of hemostasis in vivo. The main drawback is their inability to provide information about the interaction with platelets as both are measured in platelet poor plasma. Moreover, heparin concentrations exceeding $1 \mathrm{IU} / \mathrm{mL}$ cannot be accurately evaluated using the activated thromboplastin time.

The anti-Xa assay provides the only alternative to the ACT. Residual Xa in patients' plasma cleaves a chromogenic substrate, and its colored compound can be detected by spectrophotometer. Although the anti-Xa assay is thought to give good insight into heparin activity, there are limited published data evaluating its safety and effectiveness for unfractionated heparin therapy [21,22]. Currently there is no POC test available, further limiting its use during unfractionated heparin therapy for procedural anticoagulation.

\section{Future outlook}

Despite all of the recent technological advances, the ACT remains troubled by the wide variation in results. The main factors influencing 
measurements are very similar to those impacting on the coagulation system: hypothermia, hemodilution, reduced platelet count or function and coagulopathy with factor deficiency, which all prolong the ACT for a variety of reasons such as reduced enzyme activity [23], the inability to interlink fibrin or reduced platelet adhesion [24]. So far none of the manufacturers have been able to find a way to compensate for these commonly encountered conditions in order to allow more standardized results to be generated.

The introduction of the antifibrinolytic aprotinin into cardiac surgical practice initially threw the ACT into doubt as it binds the activator celite, thus leading to an artificial prolongation of the clotting time. However, kaolin emerged as the activator of choice as it is only very mildly influenced by the presence of aprotinin [25]. After a series of adverse publications, culminating in the BART trial [26], the drug's license was suspended worldwide. After numerous reviews of the evidence aprotinin is undergoing a slow process of rehabilitation $[27,28]$. Its use is currently increasing in Europe and in parts of Australia, leading the authors to speculate that celite ACT could be phased out over the next few years. There is great uncertainty if any one device is superior when using aprotinin on CPB. Several studies from around the time when aprotinin was withdrawn suggest that the Sonoclot produces more consistent results than the Hemochron Kaolin ACT and is less affected by the drug [29].

Bivalirudin is an intravenous direct thrombin inhibitor that is primarily eliminated through proteolytic cleavage and has a half-life of 25 minutes. The FDA has approved its use in patients undergoing PCI. The dosing for this indication is standardized and does not require adjustment based on repeated ACT measurements [30]. Product labeling, however, suggests that an ACT should be performed 5 minutes after a bolus dose has been given and that further bolus doses may be administered if needed. Unfortunately, no ACT value at which an additional dose is warranted has been specified [31].

The use of bivalirudin on $\mathrm{CPB}$ is more challenging and requires careful management as well as excellent communication between anesthesiologist, perfusionist and surgeon. Two randomized, controlled trials have shown bivalirudin to be safe $[32,33]$ and the latest STS / SCA / AmSECT practice guidelines for anticoagulation during CPB give it a Class IIa indication when an alternative to heparin is required [34]. The current dosing regimes of bivalirudin involve a bolus dose and a continuous infusion, suggesting that an ACT of 2.5 times baseline provides safe conditions for $\mathrm{CPB}$.

Overcoming the challenges of various influences from patientand $\mathrm{CPB}$ inherent factors, the influence of aprotinin and the ability to ascertain safe levels of coagulation when using alternative anticoagulants to heparin, will in our opinion largely determine future developments in ACT technology. The debate about appropriate anticoagulation and monitoring thereof can only become more acute, particularly in the age of increasing use of clotting factor concentrates and of prolonged mechanical support with extracorporeal membrane oxygenation in increasingly sick patients.

A confusing number of ACT devices are available. Very rarely is there a structured, lab driven process in place when an institution changes manufacturer or even only updates its ACT fleet from their current supplier. There is little awareness amongst clinicians that ACT targets cannot be used interchangeably between different devices [3537]. Implementing a new ACT device does not mean that 'business as usual' can resume after swapping one machine for another. Clinicians need to engage with lab colleagues who are very well placed to guide them through the process of safe implementation. Conversely, lab colleagues need to accept that the ACT without reference range, universally agreed target value or a true value will take them outside their comfort zone. Clinicians willing to engage in dialogue are very well placed to explain why the ACT is safe in their hands with only distant oversight.

\section{Conclusion}

The ACT has gone unchallenged for a long time. Being mostly 'clinician owned' we have come to accept that, in the absence of a gold standard, there is no way to determine if any one of the commercially available devices measures a true ACT value. Very few clinical colleagues are uncomfortable with the fact that the performance of the various devices can only be assessed in terms of reproducibility of results and not in terms of accuracy. Emerging evidence shows that devices cannot be used interchangeably, yet the target ranges during procedures requiring anticoagulation with heparin are mostly passed down to the next generation of clinicians irrespective of the particular device being used.

The way that we currently measure procedural heparin therapy in the clinical arena is old-fashioned. On the other hand it needs to be acknowledged that, despite several shortcomings, current practice is safe judging by the lack of reports of serious thromboembolic complications during procedures requiring heparin anticoagulation. The lesson to be learned from the last 40 years is that clinicians, laboratory staff's and manufacturers' approach to the ACT needs to become more collaborative, open and truly multidisciplinary in order to stand up to the level of scrutiny that is increasingly demanded in modern healthcare.

\section{Conflicts of interest}

Florian Falter Abbott POC - speaker bureau; LivaNova educational grant; JP Moulton Foundation - research grant; Evelien Kemna - none.

\section{References}

1. Di Biase L, Burkhardt JD, Mohanty P, Sanchez J, Horton R, et al. (2010) Periprocedura stroke and management of major bleeding complications in patients undergoing catheter ablation of atrial fibrillation: the impact of periprocedural therapeutic international normalized ratio. Circulation 121: 2550-2556. [Crossref]

2. Hattersley PG (1966) Activated coagulation time of whole blood. JAMA 196: 436-440 [Crossref]

3. Hill JD, Dontigny L, De Leval M, Mielke CH Jr (1974) A simple method of heparin management during prolonged extracorporeal circulation. Ann Thorac Surg 17: 129134. [Crossref]

4. Lobato RL, Despotis GJ, Levy JH, Shore-Lesserson LJ, Carlson MO, et al. (2010) Anticoagulation management during cardiopulmonary bypass: a survey of 54 North American institutions. J Thorac Cardiovasc Surg 139: 1665-1666. [Crossref]

5. Miles LF, Coulson TG, Galhardo C, Falter F (2017) Pump Priming Practices and Anticoagulation in Cardiac Surgery: Results from the Global Cardiopulmonary Bypass Survey. Anesth Analg 125: 1871-1877. [Crossref]

6. Thenappan T, Swamy R, Shah A, Nathan S, Nichols J, et al. (2012) Interchangeability of activated clotting time values across different point-of-care systems. Am J Cardiol 109: 1379-1382. [Crossref]

7. O'Gara PT, Kushner FG, Ascheim DD, Casey DE Jr, Chung MK, et al. (2013) ACCF/ AHA guideline for the management of ST-elevation myocardial infarction: executive summary: a report of the American College of Cardiology Foundation/American Heart Association Task Force on Practice Guidelines. Catheter Cardiovasc Interv 127: 529555. [Crossref]

8. Schussler JM, Aguanno JJ, Glover EN, Vish NA, Wissinger LA, et al. (2003) Comparison of the i-STAT handheld activated clotting time with the Hemochron activated clotting time during and after percutaneous coronary intervention. $\mathrm{Am} \mathrm{J}$ Cardiol 91: 464-466. [Crossref] 
9. Paniccia R, Fedi S, Carbonetto F, Noferi D, Conti P, et al. (2003) Evaluation of a new point-of-care celite-activated clotting time analyzer in different clinical settings. The i-STAT celite-activated clotting time test. Anesthesiology 99: 54-59. [Crossref]

10. Maslow A, Chambers A, Cheves T, Sweeney J (2018) Assessment of Heparin Anticoagulation Measured Using i-STAT and Hemochron Activated Clotting Time. $J$ Cardiothorac Vasc Anesth [Crossref]

11. Falter F, Razzaq N, John M, Fassl J, Maurer M, et al. (2018) Clinical Evaluation of Measuring the ACT during Elective Cardiac Surgery with Two Different Devices. $J$ Extra Corpor Technol 50: 38-43. [Crossref]

12. Lee JM, Park EY, Kim KM, Won JC, Jung TK, et al. (2018) Comparison of activated clotting times measured using the Hemochron Jr. Signature and Medtronic ACT Plus during cardiopulmonary bypass with acute normovolemic haemodilution. $J$ Int Med Res 46: 873-882. [Crossref]

13. Chia S, Van Cott EM, Raffel OC, Jang IK (2009) Comparison of activated clotting times obtained using Hemochron and Medtronic analysers in patients receiving anti-thrombin therapy during cardiac catheterisation. Thromb Haemost 101: 535-540. [Crossref]

14. Bosch YP, Ganushchak YM, de Jong DS (2006) Comparison of ACT point-of-care measurements: repeatability and agreement. Perfusion 21: 27-31. [Crossref]

15. Fowler A, Perry DJ (2015) Laboratory monitoring of haemostasis. Anaesthesia 70 Suppl 1: 68-72. [Crossref]

16. Ojito JW, Hannan RL, Burgos MM, Lim H, Huynh M, et al. (2012) Comparison of point-of-care activated clotting time systems utilized in a single pediatric institution. $J$ Extra Corpor Technol 44: 15-20. [Crossref]

17. Leyvi G, Shore-Lesserson L, Harrington D, Vela-Cantos F, Hossain S (2001) An investigation of a new activated clotting time "MAX-ACT" in patients undergoing extracorporeal circulation. Anesth Analg 92: 578-583. [Crossref]

18. Kemna EW, Kuipers C, Oude Luttikhuis-Spanjer AM, Majoor S, Boudrie R, et al. (2017) A two site comparison of two point-of-care activated clotting time systems. Clin Chem Lab Med 55: e13-13e16. [Crossref]

19. Garvin S, FitzGerald DC, Despotis G, Shekar P, Body SC (2010) Heparin concentrationbased anticoagulation for cardiac surgery fails to reliably predict heparin bolus dose requirements. Anesth Analg 111: 849-855. [Crossref]

20. Gilly G, Trusheim J (2016) Con: The Hepcon HMS Should Not Be Used Instead of Traditional Activated Clotting Time to Dose Heparin and Protamine for Cardiac Surgery Requiring Cardiopulmonary Bypass. J Cardiothorac Vasc Anesth 30: 17301732. [Crossref]

21. Bosch YPJ WP, Baheramsjah Mochtar B, Dieri RA (2014) Monitoring of Haemostasis and Anticoagulation in Cardiopulmonary Bypass Patients. J Hematol Thrombo Dis 2

22. Lennon MJ, Thackray NM, Gibbs NM (2003) Anti-factor Xa monitoring of anticoagulation during cardiopulmonary bypass in a patient with antiphospholipid syndrome. Anaesth Intensive Care 31: 95-98. [Crossref]

23. Wolberg AS, Meng ZH, Monroe DM, Hoffman M (2004) A systematic evaluation of the effect of temperature on coagulation enzyme activity and platelet function. $J$ Trauma 56: 1221-1228. [Crossref]

24. Srivastava A, Kelleher, Andrea (2013) Point-of-care coagulation testing. Continuing Education in Anaesthesia Critical Care \& Pain 13: 12-16.
25. Despotis GJ, Joist JH, Joiner-Maier D, Alsoufiev AL, Triantafillou AN, et al.. (1995) Effect of aprotinin on activated clotting time, whole blood and plasma heparin measurements. Ann Thorac Surg 59: 106-111. [Crossref]

26. Fergusson DA, Hébert PC, Mazer CD, Fremes S, MacAdams C, et al. (2008) A comparison of aprotinin and lysine analogues in high-risk cardiac surgery. $N$ Engl $J$ Med 358: 2319-2331. [Crossref]

27. Howell N, Senanayake E, Freemantle N, Pagano D (2013) Putting the record straight on aprotinin as safe and effective: results from a mixed treatment meta-analysis of trials of aprotinin. J Thorac Cardiovasc Surg 145: 234-240. [Crossref]

28. McMullan V, Alston RP (2013) III. Aprotinin and cardiac surgery: a sorry tale of evidence misused. Br J Anaesth 110: 675-678. [Crossref]

29. Dong Y, Nuttall GA, Oliver WC Jr., Agarwal S, Ereth MH (2007) Aprotinin does not prolong the Sonoclot aprotinin-insensitive activated clotting time. J Clin Anesth 19: 424-428. [Crossref]

30. Windecker S, Kolh P, Alfonso F, Collet JP, Cremer J, et al. (2014) 2014 ESC/ EACTS Guidelines on myocardial revascularization: The Task Force on Myocardial Revascularization of the European Society of Cardiology (ESC) and the European Association for Cardio-Thoracic Surgery (EACTS)Developed with the specia contribution of the European Association of Percutaneous Cardiovascular Interventions (EAPCI). Eur Heart J 35: 2541-2619. [Crossref]

31. Weeks PA, Alkhateeb HM, Michaud SE, Diez JG (2013) Evaluation of bivalirudin hyper- and hypo-ACT responses in the setting of percutaneous coronary intervention. $J$ Invasive Cardiol 25: 250-253. [Crossref]

32. Dyke CM, Smedira NG, Koster A, Aronson S, McCarthy HL $2^{\text {nd }}$, et al. (2006) A comparison of bivalirudin to heparin with protamine reversal in patients undergoing cardiac surgery with cardiopulmonary bypass: the EVOLUTION-ON study. $J$ Thorac Cardiovasc Surg 131: 533-539. [Crossref]

33. Koster A, Dyke CM, Aldea G, Smedira NG, McCarthy HL 2nd, et al. (2007) Bivalirudin during cardiopulmonary bypass in patients with previous or acute heparininduced thrombocytopenia and heparin antibodies: results of the CHOOSE-ON trial. Ann Thorac Surg 83: 572-577. [Crossref]

34. Shore-Lesserson L, Baker RA, Ferraris VA, et al. (2018) The Society of Thoracic Surgeons, The Society of Cardiovascular Anesthesiologists, and The American Society of ExtraCorporeal Technology: Clinical Practice Guidelines-Anticoagulation During Cardiopulmonary Bypass. Ann Thorac Surg 105: 650-662. [Crossref]

35. Carroll RC, Chavez JJ, Simmons JW, Snider CC, Wortham DC, et al. (2006) Measurement of patients' bivalirudin plasma levels by a thrombelastograph ecarin clotting time assay: a comparison to a standard activated clotting time. Anesth Analg 102: 1316-1319. [Crossref]

36. Jones PM, Bainbridge D, Dobkowski W, Harle CC, Murkin JM, et al. (2011) Comparison of MAX-ACT and K-ACT values when using bivalirudin anticoagulation during minimally invasive hybrid off-pump coronary artery bypass graft surgery. $J$ Cardiothorac Vasc Anesth 25: 415-418. [Crossref]

37. Aylsworth CL, Stefan F, Woitas K, Rieger RH, LeBoutillier M, et al. (2004) New technology, old standards: disparate activated clotting time measurements by the Hemochron Jr compared with the standard Hemochron. Ann Thorac Surg 77: 973-976. [Crossref]

Copyright: (C2019 Falter F. This is an open-access article distributed under the terms of the Creative Commons Attribution License, which permits unrestricted use, distribution, and reproduction in any medium, provided the original author and source are credited. 